\title{
MCHY I WAZTROBOWCE REZERWATU MOLENDA (POLSKA ŚRODKOWA)
}

\author{
MOSSES AND LIVERWORTS OF THE MOLENDA NATURE RESERVE \\ (CENTRAL POLAND)
}

\author{
Paulina Dobrowolska, Monika Staniaszek-Kik
}

\begin{abstract}
P. Dobrowolska, e-mail: paulina.dobrowolska@onet.pl
M. Staniaszek-Kik, Katedra Geobotaniki i Ekologii Roślin, Uniwersytet Łódzki, ul. Banacha 12/16, 90-237 Łódź, Poland, e-mail: monika.staniaszek@biol.uni.lodz.pl - autor korespondencyjny
\end{abstract}

\begin{abstract}
AвSTRAct. The paper presents the results of studies on bryophyte flora of the Molenda forest reserve located in the Central Poland. Fifteen species of liverworts and 73 species of mosses were found. Twenty one of these species are considered to be partially protected by law, three endangered and ten rare in the region. Epigean bryophyte constitute the largest ecological group in the bryophyte flora, consisting of 55 species $(62 \%$ of total flora), followed by epixylic species which are represented by 48 species (54\%). The most interesting were taxa threatened and regionally rare, such as Nowellia curvifolia (Dicks.) Mitt., Callicladium haldanianum (Grev.) H.A. Crum, Dicranoweisia cirrata (Hedw.) Lindb., Orthodicranum tauricum (Sapjegin) Smirnova, Orthodontium lineare Schwägr., Orthotrichum pulchellum Brunt., O. stramineum Hornsch. ex Brid., Sciuro-hypnum reflexum (Starke) Ignatov \& Huttunen, Ulota bruchii Hornsch. ex Brid. and U. crispa (Hedw.) Brid.
\end{abstract}

KEY WORDS: bryophyte, threatened species, forest communities, reserve protection

\section{WSTĘP}

Rezerwat leśny Molenda jest jednym z największych rezerwatów w województwie łódzkim (KUROwsKI \& GRZELAK 2020). Został utworzony 14 września 1959 roku, a w 2007 roku jego powierzchnia została powiększona do 147,12 ha (RozPoRZĄDZENIE... 2007). $\mathrm{W}$ granicach obiektu ochroną objęto fragment lasu mieszanego z udziałem jodły pospolitej, buka zwyczajnego i świerka pospolitego na granicy naturalnego zasięgu geograficznego tych drzew (FAGASIEWICZ 1966, Olaczek 1969, Dokumentacja... 2011).

Pierwsze próby opracowania charakterystyki florystycznej i fitosocjologicznej uroczyska Molenda były podejmowane już w 1949 roku, a następnie wznowione w latach 1962-1964. Na obszarze dzisiejszego rezerwatu w latach 1951-1964 wykonano kilka prac magisterskich opisujących zbiorowiska roślinne, a także pierwsze stanowiska mszaków tego obiektu (FAGASIEWICZ 1966). Pojedyncze dane dotyczące mchów i wątrobowców występujących w uroczysku Molenda znalazły się również w opracowaniu
ChMielewskiego i UrbaneK (1963) oraz w obszernej monografii URBANEK-RUTOWICZ (1969). Historia badań flory i roślinności na terenie rezerwatu jest więc dość długa, jednak dane odnoszące się do mszaków są niekompletne i nie stanowią faktycznego odwzorowania bioróżnorodności musko- i hepatikoflory na tym terenie. Ponadto pochodzą one sprzed ponad 50 lat, co sprawia, że konieczne jest ich zaktualizowanie. Brak nowszych informacji dotyczących mszaków spowodował, że grupa ta nie została uwzględniona $\mathrm{w}$ trakcie sporządzania ostatniego planu ochrony rezerwatu (DoKUMENTACjA... 2011). Tymczasem obecność wielu gatunków roślin zarodnikowych może stanowić pośrednie źródło informacji o stanie zachowania zbiorowisk leśnych oraz wskazywać, czy podjęte działania ochronne są skuteczne (ŻARNOWIEC 2004).

Badania prowadzone w rezerwacie Molenda miały na celu poznanie zróżnicowania flory mchów i wątrobowców występujących współcześnie w rezerwacie. Uzyskane wyniki wnoszą cenny wkład do rozpoznania regionalnych zasobów brioflory województwa łódzkiego. 


\section{CHARAKTERYSTYKA TERENU}

Rezerwat przyrody Molenda jest położony w powiecie łódzkim wschodnim, gminie Tuszyn, Nadleśnictwie Kolumna, Leśnictwie Molenda. W jego skład wchodzą następujące oddziały: 52, 53, 60, 61 i 68 oraz wydzielenia: 45f, g, i; 46d, f, h, j, k, 1, m (ryc. 1). Badany teren rozciąga się między $19^{\circ} 25^{\prime}$ i $19^{\circ} 35^{\prime} \mathrm{E}$ oraz $51^{\circ} 35^{\prime}$ i $51^{\circ} 40^{\prime} \mathrm{N}$ (kwadrat Dd 96 siatki ATMOS) (Ochyra \& Szmajda 1981). Pod względem geograficznym rezerwat jest zlokalizowany na obszarze makroregionu Wzniesień Południowomazowieckich (318.8), mezoregionu Wysoczyzny Bełchatowskiej (318.81) (Solon i in. 2018).

Obszar rezerwatu Molenda jest lekko pofałdowany $\mathrm{z}$ widocznym spadkiem w kierunku północno-wschodnim, gdzie wysokość terenu waha się między 213 a 220 m n.p.m. (FAGASIEWICZ 1966). W granicach rezerwatu dominują gleby rdzawe (rdzawe właściwe i brunatne), które zajmują ponad $44 \%$ powierzchni. Mniejszy udział mają gleby płowe (opadowoglejowe i właściwe) stanowiące $28 \%$ powierzchni oraz brunatne wyługowane $(27 \%)$. Ponadto na niewielkim obszarze stwierdzono gleby glejo-bielicowe właściwe i murszaste oraz gleby torfowe (DoKUMENTACjA... 2011). W granicach rezerwatu Molenda nie ma żadnych cieków ani zbiorników wodnych, jedynie w północnej części obiektu występują dwa zabagnienia oraz rowy odwadniające z okresowo utrzymującą się wodą.
Na badanym terenie okres wegetacyjny trwa 210$230 \mathrm{dni}$. Średnia temperatura powietrza wynosi wówczas $13^{\circ} \mathrm{C}$, a suma opadów kształtuje się na poziomie 400 mm (Fagasiewicz 1966, Dubaniewicz 1974).

Na terenie rezerwatu Molenda wyróżniono cztery zbiorowiska roślinne: grąd subkontynentalny (Tilio cordatae-Carpinetum betuli), kontynentalny bór mieszany (Querco roboris-Pinetum), śródlądowy bór wilgotny (Molinio-Pinetum) oraz ols torfowcowy (Sphagno squarrosi-Alnetum). Największą powierzchnię zajmuje grąd, w którego drzewostanie występują 150-160-letnie dęby szypułkowe Quercus robur i bezszypułkowe $Q$. petraea z domieszką grabu zwyczajnego Carpinus betulus i buka zwyczajnego Fagus sylvatica. Inne zbiorowiska występują w formie pojedynczych płatów, np. bór wilgotny został stwierdzony w dwóch miejscach -- w pododdziale $45 \mathrm{~g}$ i $46 \mathrm{~h}$, natomiast ols torfowcowy jedynie $\mathrm{w}$ pododdziale 45g (Dokumentacja... 2011).

\section{MATERIAŁ I METODY}

Badania briologiczne przeprowadzono w latach 2018-2019 metodą spisów florystyczno-ekologicznych. W pierwszym etapie $\mathrm{w}$ każdym $\mathrm{z}$ oddziałów wyznaczono po cztery stanowiska (łącznie 28 stanowisk), w obrębie których notowano i zbierano mszaki z wszystkich dostępnych typów podłoży. Stanowiska do badań starano się rozmieścić równomiernie w całym obiekcie $z$ uwzględnieniem zróżnicowania fitocenoz leśnych. Dodatkowo wykonano również spis

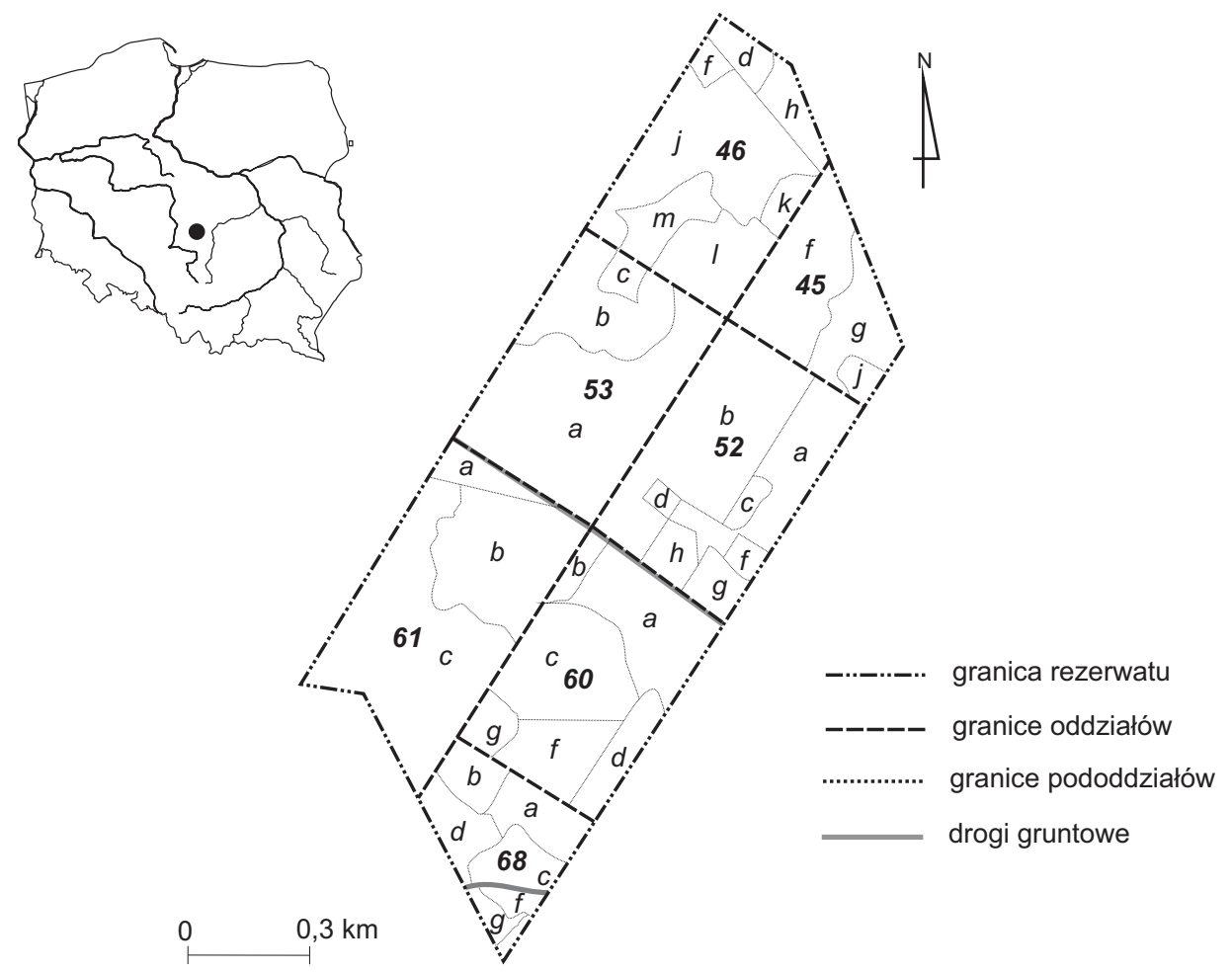

Ryc. 1. Lokalizacja rezerwatu Molenda

Fig. 1. Location of the Molenda Nature Reserve 
gatunków rosnących na duktach leśnych i w rowach. W drugim etapie badań cały obszar rezerwatu kilkukrotnie penetrowano metodą marszrutową $\mathrm{w}$ celu uchwycenia pełnego zróżnicowania briologicznego.

W pracy wyróżniono cztery grupy ekologiczne mszaków, tj. epigeity, epiksyle, epifity i epility. Do epigeitów zaklasyfikowano gatunki rosnące na: glebie, ściółce oraz mikroformach terenu związanych $z$ wykrotami. Jako epiksyle traktowano taksony rosnące na kłodach, pniakach, drobnym drewnie i martwych, stojących drzewach. Do epifitów zaliczono mszaki zasiedlające korzenie oraz korę 13 gatunków drzew: Quercus robur, Q. petraea, Pinus sylvestris, Betula pendula, B. pubescens, Acer pseudoplatanus, Carpinus betulus, Fagus sylvatica, Abies alba, Robinia pseudoacacia, Salix alba, Tilia cordata i Fraxinus excelsior. Występowanie gatunków epifitycznych notowano do wysokości $2 \mathrm{~m}$. Do epilitów zaklasyfikowano gatunki porastające głazy. Częstość występowania danego gatunku na terenie rezerwatu określono na podstawie liczby stanowisk, w których gatunek wystąpił.

Przyjęto trzystopniową skalę frekwencji: 1 - gatunek rzadki (1-20\% stanowisk), 2 - gatunek częsty $(20,1-60 \%), 3$ - gatunek pospolity $(60,1-100 \%)$. Status ochrony gatunków nadano zgodnie z Rozporządzeniem Ministra Środowiska w sprawie ochrony gatunkowej roślin (RozPoRZĄDZENIE... 2014). Grupę mszaków zagrożonych w Polsce wyodrębniono na podstawie czerwonych list za ŻARNOWCEM $\mathrm{i}$ in. (2004) oraz KLAMĄ i GórsKim (2018). Nomenklaturę dla mchów podano za Ochyrą i in. (2003), z wyjątkiem Rosulabryum moravicum (Podp.) Ochyra \& Stebel (STeBel 2006), natomiast dla wątrobowców za SzWEYKOWSKIM (2006). Materiały zielnikowe zostały zdeponowane w Herbarium Uniwersytetu Łódzkiego (LOD). Wszystkie prace $\mathrm{w}$ rezerwacie prowadzono na podstawie zezwolenia Regionalnego Dyrektora Ochrony Środowiska w Łodzi z dnia 11 maja 2018 roku, o numerze WPN.6205.28.2018.DBe, w sprawie odstępstw od zakazów w rezerwacie przyrody Molenda.

\section{WYNIKI}

W trakcie badań prowadzonych na terenie rezerwatu Molenda odnotowano 88 gatunków mszaków, w tym 73 mchy oraz 15 wątrobowców. Wśród nich 21 podlega częściowej ochronie prawnej (20 mchów i 1 wątrobowiec), a trzy (Orthotrichum stramineum, Ulota bruchii i U. crispa) znajdują się na czerwonej liście $\mathrm{w}$ kategorii narażonych na wyginięcie $(\mathrm{V})$. Na badanym obszarze stwierdzono także kilka gatunków rzadkich w Polsce środkowej. Są to: Callicladium haldanianum, Dicranoweisia cirrata, Homalia trichomanoides, Hypnum pallescens, Orthodicranum tauricum, Orthodontium lineare, Orthotrichum pallens, O. pulchellum i Sciuro-hypnum reflexum.

Najwięcej gatunków mszaków odnotowano na siedliskach epigeicznych (55), a na pozostałych odpowiednio: 48 - na epiksyliczych, 38 - na epifitycznych, 18 - na epilitycznych. Na podłożach naziemnych najczęściej notowanymi taksonami mchów były: Atrichum undulatum, Dicranella heteromalla, Herzogiella seligieri, Pleurozium schreberi oraz Polytrichastrum formosum, natomiast wśród wątrobowców dominowała Lophocolea heterophylla. Epigeity obserwowano również na tarczach korzeniowych wykrotów. Łącznie w obrębie tego mikrosiedliska stwierdzono sześć gatunków, m.in. Plagiothecium denticulatum i Dicranella heteromalla. Flora mszaków epiksylicznych występujących w rezerwacie liczyła 37 mchów i 11 wątrobowców. Najwięcej taksonów stwierdzono na murszejących kłodach (38 gatunków), a mniej na pniakach (15), drobnym drewnie (16) oraz na martwych, stojących drzewach (13). Najczęściej notowanymi mszakami na siedliskach epiksylicznych były: Hypnum cupressiforme, Orthodicranum montanum, Herzogiella seligieri oraz Lophocolea heterophylla. Grupę mchów i wątrobowców nadrzewnych reprezentowało 38 gatunków. $Z$ najwyższą frekwencją na siedliskach epifitycznych notowano: Orthodicranum montanum oraz Hypnum cupressiforme, a także: Brachytheciastrum velutinum, Brachythecium rutabulum, Lophocolea heterophylla, Metzgeria furcata, Plagiothecium laetum,

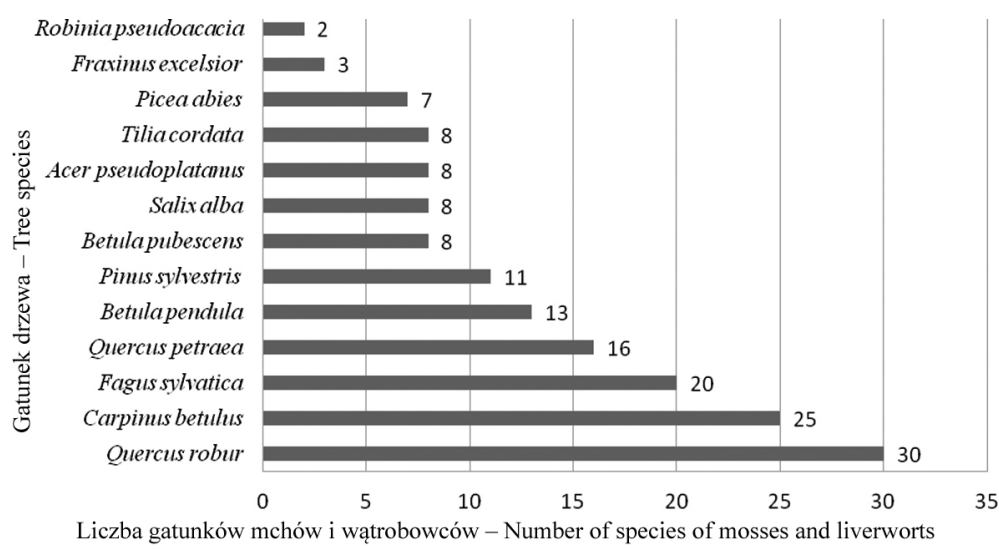

Ryc. 2. Występowanie mszaków na najczęściej spotykanych gatunkach drzew

Fig. 2. Occurrence of epiphytic mosses on the main species tree 
P. denticulatum i Platygyrium repens. Najwięcej mszaków porastało korę dębu szypułkowego Quercus robur - 30 taksonów, grabu zwyczajnego Carpinus betulus - 25 oraz buka zwyczajnego Fagus sylvatica - 20 (ryc. 2). Analiza bogactwa gatunkowego na poszczególnych gatunkach drzew wykazała znaczną różnicę pomiędzy liczbą mszaków występujących na drzewach liściastych i iglastych. W przypadku drzew liściastych odnotowano 48 taksonów (41 mchów i 7 wątrobowców), natomiast na iglastych tylko 14 (11 mchów i 3 wątrobowce). W rezerwacie Molenda podłoża epilityczne występują bardzo rzadko. Są to wyłącznie niewielkie głazy wystające $z$ gleby. Łącznie na tym typie siedliska odnotowano 16 mchów (np. Dicranum scoparium, Orthodicranum montanum, Polytrichastrum formosum) i tylko dwa wątrobowce (Lepidozia reptans i Lophocolea heterophylla).

Wśród wyróżnionych zbiorowisk leśnych na terenie rezerwatu Molenda największe zróżnicowanie mchów i wątrobowców (65 taksonów - 73,9\% ogółu brioflory) odnotowano w grądzie subkontynentalnym (Tilio cordatae-Carpinetum betuli). Do mszaków, które wystąpiły wyłącznie w tym zbiorowisku, należało 21 gatunków (np. Amblystegium serpens, Orthodontium lineare, Ptilidium pulcherrimum, Rosulabryum moravicum, Sanionia uncinata). Najczęściej notowanymi były mchy Hypnum cupressiforme i Orthodicranum montanum, a wątrobowcami --Lophocolea heterophylla i Metzgeria furcata. W kontynentalnym borze mieszanym (Querco roboris-Pinetum) stwierdzono 30 gatunków (35,3\% brioflory rezerwatu). $\mathrm{Z}$ najwyższą frekwencją występowały tu takie taksony, jak: Hypnum cupressiforme, Orthodicranum montanum, Dicranum scoparium, Lophocolea heterophylla i Plagiothecium laetum. W zbiorowisku śródlądowego boru wilgotnego (Molinio-Pinetum) odnotowano 24 taksony mszaków (29,4\% ogółu brioflory). W niewielkich płatach olsu torfowcowego (Sphagno squarrosi-Alnetum) stwierdzono 29 gatunków mszaków, które stanowiły $33 \%$ brioflory rezerwatu. Wśród zaobserwowanych taksonów osiem (10 mchów i 1 wątrobowiec) rosło wyłącznie w tym zbiorowisku (Aulacomnium palustre, Drepanocladus polycarpos, Eurhynchium angustirete, Orthotrichum pumilum, O. pulchellum, Sphagnum cuspidatum, S. russowii, Straminergon stramineum).

W granicach rezerwatu Molenda występują także nieleśne siedliska o charakterze antropogenicznym, jak rowy przydrożne oraz drogi leśne (dukty). W ich obrębie łącznie zaobserwowano 32 gatunki mszaków (28 mchów i 4 wątrobowce). Stanowiły one $36,4 \%$ brioflory rezerwatu, z czego sześć (Brachythecium albicans, Bryum rubens, Cephaloziella divaricata, Hypnum jutlandicum, Polytrichum juniperinum, Rhytidiadelphus squarossus) wystąpiło wyłącznie w tych siedliskach. W rowach i na duktach najczęściej obserwowano Atrichum undulatum, Brachythecium salebrosum, Dicranella heteromalla, Marchantia polymorpha, Plagiomnium affine, Pohlia nutans, Polytrichastrum formosum oraz Oxyrrhynchium hians.

\section{ALFABETYCZNY WYKAZ GATUNKÓW}

Listę florystyczną zestawiono w porządku alfabetycznym. Przy każdym gatunku podano kolejno następujące dane: frekwencję, charakterystykę siedliskową (podłoże i zbiorowisko), liczbę notowań, numery oddziałów (oddz.) i wydzieleń (wydz.). Gatunki zagrożone oznaczono symbolem - !, nazwy taksonów objętych ochroną częściową podkreślono. W wykazie użyto skrótów nazw łacińskich zbiorowisk roślinnych: $M-P$ - śródlądowy bór wilgotny (Molinio-Pinetum), Q-P - kontynentalny bór mieszany (Querco roboris-Pinetum), $S$-A - ols torfowcowy (Sphagno squarrosi-Alnetum), T-C - grąd subkontyntalny (Tilio cordatae-Carpinetum betuli) oraz skrótów nazw gatunkowych drzew: Aa - Abies alba, Ap - Acer pseudoplatanus, $B p-B e t u l a$ pendula, Bpu - B. pubescens, Cb-Carpinus betulus, Fe - Fraxinus excelsior, Fs - Fagus sylvatica, Ps Pinus sylvestris, $Q p-Q$. petraea, $Q r-Q u e r c u s$ robur, $R p$ - Robinia pseudoacacia, Sa - Salix alba, Tc - Tilia cordata.

\section{WĄTROBOWCE MARCHANTIOPHYTA}

Calypogeia integristipula Steph. - rzadki; gleba, $M-P$; 1 notowanie: wydz. $45 \mathrm{~g}$.

Calypogeia muelleriana (Schiffn.) Müll. Frib. - rzadki; gleba, kłoda, $M-P$; 2 notowania: wydz. 45g, 46h.

Cephalozia bicuspidata (L.) Dumort. - rzadki; gleba, kłoda, $M-P, T-C ; 2$ notowania: wydz. 45g, 53b.

Cephalozia connivens (Dicks.) Lindb. - rzadki; kora drzew (Bpu), gleba, kłoda, $M-P, S-A, T-C ; 4$ notowania: wydz. 45g, 53b, droga pomiędzy wydz. 61a i $53 \mathrm{a}$.

Cephaloziella divaricata (Sm.) Schiffn. - rzadki; gleba; 1 notowanie: rów przydrożny pomiędzy wydz. 61a i 61c.

Lepidozia reptans (L.) Dumort. - częsty; kora drzew $(B p u)$, gleba, pniaki, drobne drewno, kamienie, $M-P, Q-P, S-A, T-C ; 7$ notowań: wydz. 45g, 45i, 53a, 53b, 68b.

Lophocolea bidentata (L.) Dumort. - rzadki; gleba, T-C; 1 notowanie: wydz. 53b.

Lophocolea heterophylla (Schrad.) Dumort. - pospolity; kora drzew ( $A p, B p, C b, F s, P s, Q p, Q r)$, gleba, kłody, pniaki, drobne drewno, martwe drzewa, kamienie, $M-P$, Q-P, S-A, T-C; 25 notowań: wydz. 45f, 45g, 45i, 46d, 46j, 52b, 52f, 52h, 53a, 53b, 60a, 60c, 60f, 61c, 68a, 68b, 68c, 68d, droga pomiędzy oddz. 46 i 47 oraz 60 i 52, rów przydrożny pomiędzy wydz. 61a i 61c.

Marchantia polymorpha L. emend. Burgeff - rzadki; gleba, kłoda, T-C; 2 notowania: wydz. 53b, droga pomiędzy oddz. 60 i 52.

Metzgeria furcata (L.) Dumort. - rzadki; kora drzew (Cb, Fs, Qp, Qr), kłody, martwe drzewa, T-C; 5 notowań: wydz. 52f, 52h, 60a, 61b, 68a.

Nowellia curvifolia (Dicks.) Mitt. - rzadki; kłody, $M-P ; 2$ notowania: wydz. 45g, 46h. 
Plagiochila porelloides (Torrey ex Nees) Lindenb. rzadki; kora drzew (Bp, Qr), T-C; 1 notowanie: wydz. 53a.

Ptilidium pulcherrimum (Weber) Vain. - rzadki; kora drzew (Bpu), kłoda, T-C; 2 notowania: wydz. 53a.

Radula complanata (L.) Dumort. - rzadki; kora drzew $(\mathrm{Cb}, \mathrm{Fs}, \mathrm{Qr})$, martwe drzewa, $T-C ; 2$ notowania: wydz. 52h, 60a.

Riccia fluitans L.- rzadki; wilgotna gleba w śródleśnym zabagnieniu, kłoda, drobne drewno, T-C; 1 notowanie: wydz. 53b.

\section{BRYOPHYTA MCHY}

Amblystegium serpens (Hedw.) Schimp. - rzadki; kora drzew ( $A p, C b, F s, Q p, Q r)$, martwe drzewa, $T-C ; 4$ notowania: wydz. 45f, 52b, 53b, 60c, 60f.

Atrichum undulatum (Hedw.) P. Beauv. - częsty; kora drzew $(\mathrm{Cb})$, gleba $\mathrm{w}$ rowach przydrożnych, tarcza wykrotu, kłoda, Q-P, T-C; 13 notowań: wydz. 45f, 46d, 52b, 53a, 60c, 60f, 68a, 68b, droga pomiędzy oddz. 46 i 47, 60 i 52, 61 i 53, rów przydrożny pomiędzy wydz. 61a i 61c.

Aulacomnium androgynum (Hedw.) Schwägr. - rzadki; kłoda, Q-P; 1 notowanie: wydz. $45 i$.

Aulacomnium palustre (Hedw.) Schwägr. - rzadki; gleba, $S$ - $A ; 1$ notowanie: wydz. $45 \mathrm{~g}$.

Brachytheciastrum velutinum (Hedw.) Ignatov \& Huttunen - częsty; kora drzew ( $C b, F s, Q p$, $Q r, T c)$, gleba, kłoda, drobne drewno, kamienie $\mathrm{W}$ rowie przydrożnym, $Q-P, T-C ; 10$ notowań: wydz. 45f, 45i, 46d, 52b, 52h, 60a, $60 f$, 68a, 68b, droga pomiędzy wydz. 45g i oddz. 44.

Brachythecium albicans (Hedw.) Schimp. - rzadki; gleba $\mathrm{w}$ rowie przydrożnym; 1 notowanie: rów przydrożny pomiędzy wydz. 61a i 61c.

Brachythecium rutabulum (Hedw.) Schimp. - pospolity; kora drzew ( $A p, C b, F e, F s, Q p, Q r, T c)$, gleba, kłody, pniaki, martwe drzewo, kamienie $\mathrm{W}$ rowach przydrożnych, Q-P, T-C; 19 notowań: wydz. 45f, 46d, 52b, 52h, 53a, 53b, 60a, 60c, 60f, 61b, 61c, 68a, 68c, 68d, droga pomiędzy oddz. 60 i 52, wydz. 61a i 53a oraz wydz. 45g i oddz. 44.

Brachythecium salebrosum (Hoffm. ex F. Weber \& D. Mohr) Schimp. - częsty; kora drzew ( $\mathrm{Cb}, \mathrm{Fe}, \mathrm{Fs}$, $Q p, Q r, T c)$, gleba, kłody, drobne drewno, martwe drzewa, kamienie $\mathrm{w}$ rowach przydrożnych, $Q-P$, T-C; 14 notowań: wydz. 45i, 46d, 52b, 52f, 52h, 53a, 53b, 60f, 68a, 68c, droga pomiędzy oddz. 46 i 47, 60 i 52 oraz wydz. 61a i 53a, rów przydrożny pomiędzy wydz. 61a i 61c.

Bryum rubens Mitt. - rzadki; piaszczysta gleba na skraju lasu; 1 notowanie: wydz. 46 j.

Callicladium haldanianum (Grev.) H.A. Crum - rzadki; kora drzew $(Q r)$, kłoda, pniak, $T-C$; 3 notowania: wydz. 46j, 53a, 60a.
Calliergon cordifolium (Hedw.) Kindb. - rzadki; wilgotna gleba $\mathrm{w}$ śródleśnym obniżeniu, T-C; 1 notowanie: wydz. 53b.

Ceratodon purpureus (Hedw.) Brid. - rzadki; gleba $\mathrm{w}$ rowach przydrożnych, kłoda, $T-C$; 4 notowania: wydz. 46j, 60a, droga pomiędzy wydz. 61a i 53a, rów przydrożny pomiędzy wydz. 61a i 61c.

Dicranella cerviculata (Hedw.) Schimp. - rzadki; gleba, $M-P ; 1$ notowanie: wydz. $45 \mathrm{~g}$.

Dicranella heteromalla (Hedw.) Schimp. - częsty; gleba, tarcza wykrotu, kłody, M-P, Q-P, T-C; 15 notowań: wydz. 45g, 45i, 46d, 53a, 53b, 60a, 61b, 61c, 68a, 68b, droga pomiędzy oddz. 46 i 47, wydz. 61a i 53a oraz wydz. $45 \mathrm{~g}$ z oddz. 44, rów przydrożny pomiędzy wydz. 61a i 61c.

Dicranoweisia cirrata (Hedw.) Lindb. - rzadki; kora drzew (Qr), kłoda, T-C; 2 notowania: wydz. 53a, $60 a$.

Dicranum polysetum Sw. ex anon. - rzadki; gleba, $Q-P ; 1$ notowanie: wydz. 45i.

Dicranum scoparium Hedw. - pospolity; kora drzew $(B p, C b, P s, Q p, Q r)$, kłody, pniaki, drobne drewno, martwe drzewa, kamienie $\mathrm{w}$ rowie przydrożnym, $M-P, Q-P, S-A, T-C ; 17$ notowań: wydz. 45g, 45i, 46d, 46j, 52b, 53a, 53b, 60a, 60c, 60f, 61b, 61c, 68b, 68d, droga pomiędzy oddz. 60 i 52.

Drepanocladus polycarpos (Blandow ex Voit) Warnst. - rzadki; gleba, S-A; 1 notowanie: wydz. 45g.

Eurhynchium angustirete (Broth.) T.J. Kop. - rzadki; gleba, $S-A ; 1$ notowanie: wydz. $45 \mathrm{i}$.

Herzogiella seligeri (Brid.) Z. Iwats. - pospolity; kora drzew ( $A a, B p, P s, Q p, Q r, T c$ ), gleba, kłody, pniaki, drobne drewno, martwe drzewa w rowach przydrożnych, $M-P, Q-P, T-C ; 24$ notowania: wydz. 45f, 45g, 45i, 46d, 46j, 52b, 52f, 52h, 53a, 53b, 60a, 60c, 60f, 61b, 61c, 68a, 68b, 68c, 68d, droga pomiędzy wydz. 61a i 53a.

Homalia trichomanoides (Hedw.) Schimp. - rzadki; kora drzew $(Q r)$, kłoda, T-C; 2 notowania: wydz. 52f, 60a.

Hylocomium splendens (Hedw.) Schimp. - rzadki; gleba, T-C; 1 notowanie: wydz. 53a.

Hypnum cupressiforme Hedw. - pospolity; kora drzew ( $A a, A p, B p, B p u, C b, F s, P s, Q p, Q r$, $R p, T c)$, gleba, tarcza wykrotu, kłody, pniaki, drobne drewno, martwe drzewa, kamienie w rowach przydrożnych, $M-P, Q-P, S-A, T-C ; 25$ notowań: wydz. 45f, 45g, 45i, 46d, 46j, 52b, 52f, 52h, 53a, 53b, 60a, 60c, 60f, 61b, 61c, 68a, 68b, 68c, 68d, droga pomiędzy oddz. 60 i 52 oraz wydz. 61 i i 53 a.

Hypnum jutlandicum Holmen \& E. Warncke - rzadki; gleba $\mathrm{w}$ rowie przydrożnym; 1 notowanie: rów przydrożny pomiędzy wydz. 61a i 61c.

Hypnum pallescens (Hedw.) P. Beauv. - częsty; kora drzew ( $A p, B p, C b, F s, Q p, Q r, T c$ ), kłody, drobne 
drewno, Q-P, T-C; 14 notowań: wydz. 45i, 46d, 52b, 53a, 53b, 60a, 60c, 60f, 61c, 68a, 68b, 68c.

Isothecium alopecuroides (Lam. ex Dubois) Isov. rzadki; kora drzew ( $C b, Q r), T-C ; 3$ notowania: wydz. 53b, 60c, 61b.

Kindbergia praelonga (Hedw.) Ochyra - rzadki; gleba w rowach przydrożnych, T-C; 3 notowania: wydz. 46d, droga pomiędzy oddz. 46 i 47 oraz wydz. 61a i 53 a.

Leucobryum glaucum (Hedw.) Ångstr. - rzadki; szyja korzeniowa $(P s)$, gleba, $M-P, Q-P, T-C ; 6$ notowań: wydz. 45g, 45i, 46d, 53a, 61c, 68b.

Mnium hornum Hedw. - rzadki; kora drzew ( $Q p)$, gleba, kłoda, kamienie, $M-P, Q-P, T-C ; 4$ notowania: wydz. 45g, 46d, 53a, 61c.

Orthodicranum flagellare (Hedw.) Loeske - częsty; humus, kłody, pniaki, drobne drewno w rowie przydrożnym, $M-P, Q-P, S-A, T-C ; 11$ notowań: wydz. 45g, 45i, 46d, 53a, 53b, 60f, 61c, 68a, droga pomiędzy wydz. 61a i 53a.

Orthodicranum montanum (Hedw.) Loeske - pospolity; kora drzew $(B p u, Q p)$, gleba, kłody, pniaki, drobne drewno, martwe drzewa, kamienie w rowach przydrożnych, $M-P, Q-P, S-A, T-C ; 21$ notowań: wydz. 45f, 45g, 46d, 46j, 52b, 52f, 52h, 53a, 53b, 60a, 60f, 61c, 68a, 68b, 68c, 68d, droga pomiędzy oddz. 46 i 47 oraz 60 i 52.

Orthodicranum tauricum (Sapjegin) Smirnova - częsty; kora drzew $(B p, C b, Q r)$, kłody, pniaki, $Q-P$, T-C; 9 notowań: wydz. 53a, 60a, 60c, 60f, 61b, 61c, 68a, 68b, 68d.

Orthodontium lineare Schwägr. - rzadki; kora drzew (Ps), T-C; 1 notowanie: wydz. 46d.

Orthotrichum affine Schrad. ex Brid. - rzadki; kora drzew ( $A p, C b, S a)$, kłody, $S-A, T-C ; 5$ notowań: wydz. 45g, 46j, 52b, 60a, 68a.

Orthotrichum diaphanum Schrad. ex Brid. - rzadki; kora drzew ( $C b, S a), S-A, T-C ; 2$ notowania: wydz. 45g, 46j.

Orthotrichum pallens Bruch ex Brid. - rzadki; kora drzew (Sa), T-C; 1 notowanie: wydz. 52b.

Orthotrichum pulchellum Brunt. - rzadki; kora drzew (Sa), $S-A ; 1$ notowanie: wydz. 45g.

Orthotrichum pumilum Sw. ex anon. - rzadki; kora drzew (Sa), $S-A$; 1 notowanie: wydz. 45g.

Orthotrichum speciosum Nees - rzadki; kora drzew (Cb, Sa), S-A, T-C; 2 notowania: wydz. 45g, 46j.

! Orthotrichum stramineum Hornsch. ex Brid. - rzadki; kłoda, T-C; 1 notowanie: wydz. 52b.

Oxyrrhynchium hians (Hedw.) Loeske - częsty; gleba w rowach przydrożnych, T-C; 7 notowań: wydz. 46j, 52b, 60a, 60f, 68a, droga pomiędzy wydz. 45g i oddz. 44, wydz. 61a i 53a oraz rów przydrożny pomiędzy wydz. 61a i 61c.

Plagiomnium affine (Blandow ex Funck) T.J. Kop. - częsty; kora drzew (Qp, Qr), gleba, kłody w rowach przydrożnych, $Q-P, T-C ; 9$ notowań: wydz. 46d, 53a, 60a, 61c, 68c, droga pomiędzy wydz. 45g i oddz. 44, oddz. 60 i 52 oraz wydz. 61a i 53a, rów przydrożny pomiędzy wydz. 61a i $61 \mathrm{c}$.

Plagiomnium cuspidatum (Hedw.) T.J. Kop. - rzadki; kora drzew ( $F s, Q p Q r)$, kłoda w rowie przydrożnym, $T-C$; 4 notowania: wydz. 52b, 60a, 60c, droga pomiędzy oddz. 46 i 47 .

Plagiothecium curvifolium Schlieph. ex Limpr. - częsty; kora drzew $(A a, B p, C b, Q p, Q r)$, kłody, pniaki, martwe drzewa, kamienie, $M-P, Q-P, T-C ; 13$ notowań: wydz. 45g, 45i, 46j, 52f, 52h, 53a, 60a, 60c, 61c, 68a, 68b, 68c.

Plagiothecium denticulatum (Hedw.) Schimp. - częsty; kora drzew $(A a, B p, C b, F s, Q p, Q r, T c)$, gleba, tarcza wykrotu, kłody w rowach przydrożnych, $Q-P, T-C$; 10 notowań: wydz. 45i, 46d, 52b, 52f, 52h, 53a, 68a, droga pomiędzy oddz. 60 i 52 oraz wydz. 45g i oddz. 44.

Plagiothecium laetum Schimp. - częsty; kora drzew $(A a, B p, C b, F s, P s, Q p, Q r)$, gleba, kłody, pniaki, kamienie w rowach przydrożnych, $M-P, Q-P, T-C$; 11 notowań: wydz. 45f, 45g, 45i, 46d, 53a, 60a, 60c, 60f, 61b, 68b, rów przydrożny pomiędzy wydz. 61a i 61c.

Platygyrium repens (Brid.) Schimp. - częsty; kora drzew ( $A p, C b, F s, Q p, Q r, S a$ ), kłody, drobne drewno, martwe drzewa, kamienie $\mathrm{w}$ rowie przydrożnym, Q-P, T-C; 15 notowań: wydz. 45f, 52b, 52f, 52h, 53a, 53b, 60a, 60c, 60f, 61b, 68a, 68b, 68c, 68d, droga pomiędzy oddz. 60 i 52.

Pleurozium schreberi (Willd. ex Brid.) Mitt. - częsty; gleba, kłody, pniaki w rowach przydrożnych, $M-P$, Q-P, S-A, T-C; 9 notowań: wydz. 45i, 45g, 53a, 61c, 68b, droga pomiędzy wydz. 45g i oddz. 44 oraz oddz. 60 i 52.

Pohlia nutans (Hedw.) Lindb. - częsty; kora drzew $(B p u)$, gleba, pniaki, drobne drewno, kamienie w rowach przydrożnych, $M-P, Q-P, S-A, T-C$; 8 notowań: wydz. 45g, 45i, 53b, 68b, droga pomiędzy wydz. 45g i oddz. 44 oraz wydz. 61a i 53a, rów przydrożny pomiędzy wydz. 61a i 61c.

Polytrichastrum formosum (Hedw.) G.L. Sm. - pospolity; kora drzew $(Q r)$, gleba, tarcza wykrotu, kamienie w rowach przydrożnych, $M-P, Q-P$, $S-A, T-C ; 17$ notowań: wydz. 45f, 45g, 45i, 52h, 53a, 53b, 60a, 60c, 61b, 61c, 68a, 68b, droga pomiędzy wydz. 45g i oddz. 44, oddz. 46 i 47 oraz oddz. 60 i 52, rów przydrożny pomiędzy wydz. 61a i 61c.

Polytrichum commune Hedw. - rzadki; gleba, Q-P, $S-A ; 2$ notowania: wydz. $45 \mathrm{~g}, 46 \mathrm{~m}$.

Polytrichum juniperinum Hedw. - rzadki; gleba w rowie przydrożnym; 1 notowanie: rów przydrożny pomiędzy wydz. 61a i 61c.

Pseudoscleropodium purum (Hedw.) M. Fleisch. ex Broth. - rzadki; gleba, Q-P; 3 notowania: 61c, $68 \mathrm{~b}$ oraz rów przydrożny pomiędzy wydz. 61a i $61 \mathrm{c}$. 
Pylaisia polyantha (Hedw.) Schimp. - rzadki; kora drzew ( $C b, F e, S a, T c)$, kłoda, $S-A, T-C ; 3$ notowania: wydz. 45g, 52b, 60a.

Rhizomnium punctatum (Hedw.) T.J. Kop. - rzadki; kłoda, drobne drewno, T-C; 3 notowania: wydz. 53b, droga pomiędzy oddz. 46 i 47 oraz wydz. 61a i 53 a.

Rhytidiadelphus squarrosus (Hedw.) Warnst. - rzad$\mathrm{ki}$, kamień w rowie przydrożnym; 1 notowanie: droga pomiędzy oddz. 60 i 52.

Rosulabryum capillare (Hedw.) J.R. Spence - rzadki; kora drzew (Fs), kłody, T-C; 3 notowania: wydz. 60a, 60f, 68a.

Rosulabryum moravicum (Podp.) Ochyra \& Stebel rzadki; kora drzew ( $C b, F s, Q r)$, gleba, kłody, $T-C$; 4 notowania: wydz. 52h, 53b, 60a, 68a.

Sanionia uncinata (Hedw.) Loeske - rzadki; gleba w śródleśnym obniżeniu, $T$-C; 1 notowanie: wydz. $53 \mathrm{~b}$.

Sciuro-hypnum oedipodium (Mitt.) Ignatov \& Huttunen - częsty; kora drzew (Qr), gleba, kłody, rowy przydrożne, $M-P, Q-P, S-A, T-C ; 11$ notowań: wydz. 45g, 45i, 46h 52h, 53b, 60a, 60c, 68b, 68c, droga pomiędzy wydz. 45g i oddz. 44 oraz oddz. 60 i 52.

Sciuro-hypnum populeum (Hedw.) Ignatov \& Huttunen - rzadki; kora drzew $(C b), T-C ; 1$ notowanie: wydz. 60a.

Sciuro-hypnum reflexum (Starke) Ignatov \& Huttunen - rzadki; kora drzew (Fs), kłoda, T-C; 1 notowanie: wydz. 60a.

Sphagnum capillifolium (Ehrh.) Hedw. - rzadki; gleba, $M-P, T-C ; 2$ notowania: wydz. 45g, 53a.

Sphagnum cuspidatum Ehrh. ex Hoffm. - rzadki; gleba, $S$ - $A ; 1$ notowanie: wydz. $45 \mathrm{~g}$.

Sphagnum fallax (H.Klinggr.) H. Klinggr. - rzadki; gleba, S-A, T-C; 2 notowania: wydz. 45g, 53b.

Sphagnum fimbriatum Wilson - rzadki; gleba, kłoda, $M-P, Q-P, S-A, T-C ; 4$ notowania: wydz. 45g, 46m, 53b.

Sphagnum palustre L. - rzadki; gleba, kłoda, M-P, $S-A, T-C ; 3$ notowania: wydz. 45g, 53b.

Sphagnum russowii Warnst. - rzadki; gleba, $S-A ; 1$ notowanie: wydz. $45 \mathrm{~g}$.

Straminergon stramineum (Dicks. ex Brid.) Hedenäs - rzadki; gleba, $S-A ; 1$ notowanie: wydz. 45g.

Tetraphis pellucida Hedw. - częsty; humus, kora drzew ( $A a, B p u, F s, P s, Q p, Q r$ ), gleba, tarcza wykrotu, pniaki, drobne drewno, kamienie, $M-P, Q-P$, S-A, T-C; 13 notowań: wydz. 45f, 45g, 45i, 46d, 46m, 53a, 53b, 60a, 60f, 68a, 68b, 61c.

Thuidium tamariscinum* (Hedw.) Schimp. - rzadki; kora drzew (Qr), gleba, kłody, drobne drewno, kamienie, $M-P, Q-P, T-C ; 6$ notowań: wydz. 45g, 52f, 53a, 53b, 68a, 68b.

! Ulota bruchii Hornsch. ex Brid. - rzadki; kora drzew (Cb), T-C; 1 notowanie: wydz. 46j.

! Ulota crispa (Hedw.) Brid. - rzadki; kora drzew ( $\mathrm{Cb}$, Fs), T-C; 2 notowania: wydz. 60a, $61 \mathrm{~b}$.

\section{DYSKUSJA}

Rezerwat Molenda jest jednym z kilkunastu rezerwatów leśnych w Polsce środkowej, chroniących zbiorowiska $\mathrm{z}$ jodłą pospolitą na granicy jej naturalnego zasięgu. Bogactwo gatunkowe mszaków w tych obiektach jest dość zróżnicowane. Dla porównania, w rezerwacie Jamno stwierdzono 57 taksonów (WoLsKI i in. 2012), w Jodłach Oleśnickich - 45 (WoLsKI \& Fudali 2013), w Kruszewcu - 68 (Wolski \& Fudali 2014), a w Łaznowie - 46 (WolsKi \& JAKUBOWSKA-GABARA 2010). Na ich tle flora mchów i wątrobowców rezerwatu Molenda licząca 88 gatunków jest bardzo bogata i stanowi $28 \%$ ogółu brioflory Polski środkowej (Staniaszek-KiK \& Wolski 2009). Czynnikami, które wywierają wpływ na znaczne zróżnicowanie gatunkowe mchów i wątrobowców w obiektach chronionych, są: rozległość areału i stopień fragmentacji, stopień zachowania zbiorowisk roślinnych oraz oddziaływanie człowieka (Stebel i in. 2017). W przypadku rezerwatu Molenda jego duża powierzchnia (147 ha) sprzyja zachowaniu dużej bioróżnorodności. Wykazano bowiem, że dopiero rezerwaty o areale większym niż 100 ha są w stanie zapewnić właściwą ochronę szacie roślinnej m.in. dzięki minimalizowaniu negatywnego wpływu gospodarki leśnej czy nadmiernej penetracji przez człowieka (BABCZYŃSKA-SENDeK i in. 1993, Stebel 2014, Stebel i in. 2017).

W rezerwacie Molenda odnotowano występowanie mszaków z czterech grup ekologicznych, porastających osiem różnych typów podłoży, z czego szczególnie bogato reprezentowane były epigeity. W porównaniu z innymi podobnymi obiektami w Polsce środkowej, tylko w rezerwacie „Łaznów” mszaki naziemne były najbogatszą grupą ekologiczną (WoLSKI \& JAKUBOWSKA-GABARA 2010). W składzie gatunkowym dominowały Polytrichastrum formosum, Atrichum undulatum oraz Dicranella heteromalla - pospolite mchy leśne (Stebel 2006). Dużym zróżnicowaniem mszaków naziemnych cechowały się dukty i przydrożne rowy, które tworzą szczególny rodzaj mikrosiedliska, kolonizowany nie tylko przez mszaki leśne (Wolski \& Fudali 2013, Staniaszek-Kik i in. 2016). W rezerwacie Molenda są one ostoją gatunków światłożądnych, nieleśnych, m.in. Brachythecium albicans, Polytrichum juniperinum czy Rhytidiadelphus squarrosus. Ponadto obecność rowów przydrożnych i odwadniających ma duże znaczenie w przypadku wątrobowców. Na stromych skarpach często dochodzi do obsuwania się ściółki, a odsłonięte podłoże mineralne stwarza dogodne warunki do rozwoju hepatikoflory. Wyłącznie w obrębie tego mikrosiedliska pojawiają się obfite populacje Cephalozia bicuspidata, Calypogeia integristipula i Cephaloziella divaricata. W zbiorowiskach leśnych gatunki te często porastają wykroty, a w przypadku ich braku chętnie zajmują glebę mineralną na stromych skarpach rowów (STANIASZEK-KIK i in. 2016). 
Drugim, najbogatszym pod względem liczby gatunków mszaków siedliskiem były siedliska epiksyliczne. W rezerwacie Molenda epiksyle stanowiły $56 \%$ ogółu brioflory. Wyniki badań prowadzonych $\mathrm{w}$ innych rezerwatach $\mathrm{w}$ Polsce środkowej były podobne: Łaznów - 50\% (WolsKi \& JAKUBOWSKA-GABARA 2010), Kruszewiec - 60\% (WolsKi \& FudAli 2014), Jodły Oleśnickie - 69\% (Wolski \& Fudali 2013), Jamno - 56\% (Wolski i in. 2012). Tak duży odsetek gatunków zasiedlających rozkładające się drewno potwierdza, jak ważne i kluczowe znaczenie ma ten substrat dla bioróżnorodności mszaków w ekosystemach leśnych (ANDERsson \& HytTeborn 1991, FojCiK 2011, WiERZGOŃ \& FoJCIK 2014). Wśród odnotowanych epiksyli znacznie więcej taksonów zaobserwowano na kłodach niż na pniakach. Kłody, w porównaniu $\mathrm{z}$ pniakami, są bardziej nasycone wilgocią, zapewniają więcej miejsca do zasiedlania, a także wolniej zanikają, co pozwala na ich dłuższe kolonizowanie przez mszaki (Friedel i in. 2006, JANSOvÁ \& Soldán 2006, Ódor i in. 2006, KushnevsKaya i in. 2007, RaJANDU i in. 2009, StANIASZEK-KIK \& ŻARNOWIEC 2017). W dobrze zachowanych lasach obecność kłód o dużych rozmiarach znacząco wpływa na zwiększenie różnorodności, zwłaszcza wątrobowców (KLAMA 2002, Ódor i in. 2006, Rajandu i in. 2009, FojCIK 2011). W rezerwacie Molenda odnotowano występowanie rzadkiego, obligatoryjnego epiksyla, jakim jest Nowellia curvifolia. Wątrobowiec ten w województwie łódzkim został stwierdzony dotychczas na jednym stanowisku w rezerwacie Wolbórka (URBANEK-RUTOwicz 1969). W Polsce $N$. curvifolia znana jest głównie ze wschodniej części kraju (SzweYKowski 1969, KLAMA 2002), ale w ostatnich kilkunastu latach stwierdzono ją na coraz liczniejszych stanowiskach także w innych regionach (Stebel 2002, Górski 2010, 2013, Stebel \& SMOLIŃSKa 2013, GóRSKI i in. 2014, 2015a, b, c, 2016). Powyższemu zjawisku mogą sprzyjać zmiany w prowadzeniu gospodarki leśnej, zwłaszcza zwiększanie zasobów martwego drewna w lasach.

Różnorodność gatunkowa epifitów w zbiorowiskach leśnych jest determinowana wieloma czynnikami, m.in. strukturą lasu i wiekiem drzewostanu. W starodrzewach i lasach wielopokoleniowych wskaźnik zasobności drzewostanu osiąga wartości niespotykane w lasach gospodarczych. Są to uprzywilejowane warunki dla dynamiki procesu kolonizacji siedlisk przez mszaki (BARKMAN 1958, FoנcIK 2011). W rezerwacie Molenda niektóre drzewa mają ponad 160 lat, co przekłada się na liczbę oraz skład gatunkowy epifitów. W wydzieleniu $60 \mathrm{a}$, w obrębie jednego z najstarszych zachowanych płatów drzewostanu, odnotowano 20 gatunków epifitycznych, w tym m.in. Homalia trichomanoides, Ulota crispa i Orthotrichum speciosum. Wiek drzewa wpływa także na strukturę kory, która $z$ upływem czasu staje się bardziej chropowata i spękana, co sprzyja osiedlaniu się diaspor mszaków (BARKMAN 1958).
Siedliska naskalne, do których zaliczono jedynie nieliczne śródleśne głazy pojawiające się na terenie rezerwatu Molenda, charakteryzowały się ubóstwem musko- i hepatikoflory. Spośród odnotowanych gatunków w tej grupie pojawiły się typowe naziemne mchy leśne, które są zdolne do wkraczania na podłoża skalne, np. Mnium hornum i Polytrichastrum formosum, a także fakultatywne epility, do których należy większość pospolitych gatunków ubikwistycznych, np. Hypnum cupressiforme i Brachythecium rutabulum (FoJCIK 2011).

Różnorodność gatunkowa mszaków jest ściśle powiązana $z$ typem zbiorowiska leśnego, ponieważ rośliny wyższe determinują mezoklimat wewnątrz zbiorowiska (ŻARNOWIEC $\mathrm{i}$ in. 1996). W rezerwacie Molenda największe bogactwo gatunkowe zaobserwowano $\mathrm{w}$ grądzie subkontynentalnym (Tilio cordatae-Carpinetum betuli), który jest jednocześnie dominującym zbiorowiskiem w omawianym obiekcie. $\mathrm{Na}$ wzrost bogactwa gatunkowego w rezerwacie Molenda znacząco wpływa obecność niewielkich płatów olsu torfowcowego (Sphagno squarrosi-Alnetum). Jest to bowiem ostoja dla gatunków higro- i hydrofilnych, np. Aulacomnium palustre, Straminergon stramineum, Polytrichum commune oraz torfowców.

Na obszarze rezerwatu Molenda stwierdzono stanowiska czterech mchów - Orthodicranum tauricum, Dicranoweisia cirrata, Callicladium haldanianum oraz Orthodontium lineare, których zasięgi współcześnie zwiększają się (Stebel 2006, Fojcik 2011). Orthodicranum tauricum pierwszy raz na terenie Polski został odnotowany w 1922 roku, a od lat 80. XX wieku obserwuje się jego ciągłą ekspansję. Obecnie znany jest $z$ ponad 200 stanowisk na terenie całego kraju (Stebel i in. 2012a, b). W rezerwacie Molenda zaobserwowano go na dziewięciu stanowiskach w kontynentalnym borze mieszanym (Querco roboris-Pinetum) i grądzie subkontynentalnym (Tilio cordatae-Carpinetum betuli), gdzie porastał korę drzew, a także kłody i pniaki. W przypadku Dicranoweisia cirrata szybki wzrost liczby stanowisk obserwuje się od lat 90 . (Stebel \& PlášeK 2001). W rezerwacie Molenda Dicranoweisia cirrata odnotowano $\mathrm{w}$ dwóch lokalizacjach $\mathrm{w}$ grądzie subkontynentalnym (Tilio cordatae-Carpinetum betuli), gdzie porastał szyję korzeniową Quercus robur oraz murszejącą kłodę. Callicladium haldanianum do połowy XX wieku znany był jedynie z rozproszonych lokalizacji. Obecnie jest częstym lub pospolitym gatunkiem we wschodniej, środkowej i południowej Polsce. Występuje zarówno w naturalnych, jak i gospodarczych lasach, gdzie porasta najczęściej kłody i pniaki (Stebel 2013). W rezerwacie Molenda C. haldanianum odnotowano na trzech stanowiskach $\mathrm{w}$ grądzie subkontynentalnym (Tilio cordatae-Carpinetum betuli), gdzie wystąpił na pniu, kłodzie oraz szyi korzeniowej dębu szypułkowego Quercus robur. Ostatnim gatunkiem zaliczonym do rozprzestrzeniających się w regionie jest Orthodontium lineare. Jest to 
gatunek obcy, który po raz pierwszy został odnotowany w Polsce w 1982 roku. Aktualne dane wskazują, że ciągle zwiększa swój areał na terenie kraju, szczególnie na wschodzie, co prawdopodobnie jest spowodowane zakwaszeniem środowiska. Obserwowany jest u podstawy pni drzew z kwaśną korą (Pinus sylvestris, Quercus robur) oraz na rozkładajacym się drewnie, głównie w lasach liściastych i mieszanych (FudAli i in. 2009, ŻARNOWIEC $i$ in. 2020). Na obszarze objętym badaniami Orthodontium lineare odnotowano tylko raz $\mathrm{w}$ grądzie subkontynentalnym (Tilio cordatae-Carpinetum betuli), na szyi korzeniowej sosny zwyczajnej Pinus sylvestris.

W wyniku przeprowadzonych badań udało się potwierdzić większość taksonów notowanych w latach 50. i 60. Nie odnaleziono 13 gatunków: Atrichum angustatum, Climacium dendroides, Plagiomnium rostratum, Polytrichum piliferum, Ptilium crista-castrensis, Syntrichia ruralis, Tortula subulata, Warnstorfia fluitans, Blepharostoma trichophyllum, Scapania irrigua, Scapania nemorea, Lophocolea minor i Lophozia bicrenata. Być może występują one poza granicami rezerwatu, ponieważ stanowiska historyczne często odnoszą się do uroczyska Molenda, a obecnie istniejący rezerwat obejmuje tylko część tego dużego kompleksu leśnego. Wśród gatunków niestwierdzonych współcześnie znalazł się $\mathrm{m}$.in. Plagiomnium rostratum, dla którego w rezerwacie Molenda nie było potencjalnych siedlisk, co może wskazywać na błąd przy oznaczeniu. Niestety, brak materiału zielnikowego uniemożliwia potwierdzenie lub odrzucenie tej hipotezy.

Współczesny stan zachowania brioflory rezerwatu Molenda należy uznać za zadowalający. Świadczy o tym m.in. występowanie znacznej liczby gatunków mszaków chronionych, zagrożonych i rzadkich w regionie. Rezerwat z całą pewnością stanowi cenny przyrodniczo obiekt.

\section{LITERATURA}

Andersson L.I., Hytteborn H. (1991): Bryophytes and decaying wood - comparison between managed and natural forest. Holarctic Ecology 14: 121-130.

BabczyńsKa-Sendek B., Cabata S., Kimsa T., Wika S. (1993): Wielkość rezerwatów a stan zachowania ich szaty roślinnej na przykładzie województw częstochowskiego i katowickiego. Prądnik, Prace i Materiały Muzeum im. W. Szafera 7-8: 257-266.

BARKMAN J.J. (1958): Phytosociology and ecology of cryptogamic epiphytes. Including a taxonomic survey and description of their vegetation units in Europe. Van Gorcum \& Comp. N.V., Assen, Netherlands.

Chmielewski T., Urbanek H. (1963): Mszaki okolic Łodzi (wątrobowce i torfowce). Łódzkie Towarzystwo Naukowe, Sprawozdanie z Czynności i Posiedzeń 17(4): 1-16.
DoKUMENTACjA do projektu planu ochrony rezerwatu „Molenda” na okres od 1 stycznia 2012 roku do 31 grudnia 2031 roku. (2011). Krameko, Kraków.

Dubaniewicz H. (1974): Klimat województwa łódzkiego. Acta Geographica Lodziensia 34: 1-113.

FAGASIEWICZ L. (1966): Rezerwat jodłowy Molenda pod Łodzią. Zeszyty Naukowe Uniwersytetu Łódzkiego, Nauki Matematyczno-Przyrodnicze 2(22): 43-81.

Fојсік B. (2011): Mchy Wyżyny Krakowsko-Częstochowskiej w obliczu antropogenicznych przemian szaty roślinnej. Wydawnictwo Uniwersytetu Śląskiego, Katowice.

Friedel A., Oheimb G.V., Dengler J., Härdtle W. (2006): Species diversity and species composition of epiphytic bryophytes and lichens - a comparison of managed and unmanaged beech forests in NE Germany. Feddes Repertorium 117(1-2): 172-185.

Fudali E., Szczepański M., RusińsKa A., RosadzińsKi S., Wolski G. (2009): The current distribution in Poland some European neophytic bryophytes with supposed invasive tendencies. Acta Societatis Botanicorum Poloniae 78(1): 73-80.

GóRSKI P. (2010): A contribution to the liverwort flora of the Drawsko Lake district (Western Pomerania, Poland). Roczniki Akademii Rolniczej w Poznaniu 389, Botanika-Steciana 14: 19-26.

GóRSKI P. (2013): Wątrobowce (Marchantiophyta) Leśnego Kompleksu Promocyjnego „Lasy Środkowopomorskie" (Pomorze Zachodnie). Nadleśnictwo Karnieszewice - Wydawnictwo Uniwersytetu Przyrodniczego w Poznaniu, Poznań.

Górski P., Pawlikowski P., Staniaszek-Kik M., RosaDZiński S., Stebel A., Rusińska A., Zubel R., Wilhelm M., Fudali E., Cykowska-Marzencka B., PrzewoźniK L. (2014): New distributional data on bryophytes of Poland, 1. Steciana 18(2): 77-87.

Górski P., Smoczyk M., Pawlikowski P., Vončina G., Stebel A., Paciorek T., Staniaszek-Kik M., Romański M., Wiaderny A., GąbKa M., Wierzcholska S. (2015a): New distributional data on bryophytes of Poland, 2. Steciana 19(2): 55-65.

Górski P., Rosadziński S., Rusińska A., Pawlikowski P., Wilhelm M., Zubel R., Piwowarski B., StaniaSZEK-KIK M., Fojcik B., WoŁkowycki D., Lisowski S., Pisarek W., Anioe A., Tracz J. (2015b): New distributional data on bryophytes of Poland and Slovakia, 3. Steciana 19(3): 163-176.

Górski P., Kapustyński T., Kozub Ł., Dembicz I., RosaDZIŃSKi S., StANIASZEK-KiK M., RusiŃSKa A., SMOCZYK M. (2015c): New distributional data on bryophytes of Poland and Slovakia, 4. Steciana 19(4): 221-230.

Górski P., Vončina G., SMoczyk M., Klama H., Šoltés R., Wilhelm M., RutKowska M. (2016): New distributional data on bryophytes of Poland and Slovakia, 8. Steciana 20(4): 191-200. 
JansovÁ I., SoldÁn Z. (2006): The habitat factors that affect the composition of bryophyte and lichen communities on fallen logs. Preslia 78: 67-86.

Klama H. (2002): Distribution patterns of liverworts (Marchantiopsida) in natural forest communities (Białowieża Primeval Forest, NE Poland). University of Bielsko-Biała, Bielsko-Biała.

Klama H., Górski P. (2018): Red list of liverworts and hornworts of Poland (4th edition, 2018). Cryptogamie, Bryologie 39(4): 415-441.

Kurowski J.K., Grzelak P. (red.) (2020): Rezerwaty przyrody w województwie łódzkim - przeszłość, teraźniejszość, przyszłość. Wydawnictwo Klubu Przyrodników, Świebodzin.

Kushnevskaya H., Mirin D., Shorohova E. (2007): Patterns of epixylic vegetation on spruce logs in late-succesional boreal forests. Forest Ecology and Management 250: 25-33.

Ochyra R., Szmajda P. (1981): La cartographie bryologique en Pologne. W: J. Szweykowski (red.). New perspectives in bryotaxonomy and bryogeography. Uniwersytet im. Adama Mickiewicza w Poznaniu, Seria Biologica 20: 105-107.

Ochyra R., Żarnowiec J., Bednarek-Ochyra H. (2003): Census catalogue of Polish mosses. Instytut Botaniki im. W. Szafera, PAN, Kraków.

Ódor P., Heilmann-Clausen J., Christensen M., Aude E., van Dort K.W., Piltaver A., Siller I., Veerkamp M.T., Walleyn R., Standovár T., van Hees A.F.M., Kosec J., Matočec N., Kraigher H., Grebenc T. (2006): Diversity of dead wood inhabiting fungi and bryophytes in semi-natural beech forests in Europe. Biological Conservation 131: 58-71.

OlaczeK R. (1969): Rezerwaty Molenda i Wolbórka w lasach tuszyńskich. Przewodnik dydaktyczny dla nauczycieli. Liga Ochrony Przyrody - Zarząd Okręgu Łódzkiego, Łódź.

Rajandu E., Kikas K., PaAl J. (2009): Bryophytes and decaying wood in Hepatica site-type boreo-nemoral Pinus sylvestris forests in Southern Estonia. Forest Ecology and Management 257: 994-1003.

RozPORZĄDZENIE nr 38/2007 Wojewody Mazowieckiego z dnia 18 lipca 2007 r. w sprawie rezerwatu przyrody „Molenda”. (2007). Dz.Urz. Woj. Łódzkiego Nr 243, poz. 2249.

RozPoRZĄDZENIE Ministra Środowiska $z$ dnia 9 października 2014 r. w sprawie ochrony gatunkowej roślin. (2014). Dz.U. 2014, poz. 1409.

Solon J., Borzyszkowski J., BidŁasiK M., Richling A., Badora K., Balon J., Brzezińska-Wójcik T., ChabudziŃski Ł., Dobrowolski R., GrZegorczyk I., JoDŁowski M., Kistowski M., Kot R., KRĄż P., LeChNiO J., Macias A., Majchrowska A., Malinowska E., Migoń P., Myga-Piątek U., Nita J., Papińska E., RodZiK J., Strzyż M., TerpiŁowski S., Ziaja W. (2018): Physico-geographical mesoregions of Poland: Verification and adjustment of boundaries on the basis of contemporary spatial data. Geographia Polonica 91(2): 143-170.

StaniaszeK-KiK M., Wolski G. (2009): Mszaki - zróżnicowanie, zmiany i zagrożenia. W: J.K. Kurowski (red.). Szata roślinna Polski środkowej. Towarzystwo Ochrony Krajobrazu, Wydawnictwo Eko-Graf, Łódź: 48-56.

Staniaszek-Kik M., ZielińsKa K.M., MiszTal M. (2016): How do ditches contribute to bryophyte diversity in managed forests in East-Central Europe? European Journal of Forest Research 135(4): 621-632.

StANIASZEK-KIK M., ŻARNOWIEC J. (2017): Diversity of mosses on stumps and logs in the Karkonosze Mts (Sudetes Mts, Central Europe). Herzogia 31: $70-87$.

Stebel A. (2002): Materiały do brioflory Parku Narodowego Bory Tucholskie (Pomorze Zachodnie). Parki Narodowe i Rezerwaty Przyrody 21(2): 159-175.

Stebel A. (2006): The mosses of the Beskidy Zachodnie as a paradigm of biological and environmental changes in the flora of the Polish Western Carpathians. Śląski Uniwersytet Medyczny w Katowicach i Wydawnictwo Sorus, Katowice-Poznań.

Stebel A. (2013): Distribution of Callicladium haldanianum (Bryophyta, Hypnaceae) in Poland. Polish Botanical Journal 58(2): 593-603.

Stebel A. (2014): Różnorodność gatunkowa mszaków rezerwatu leśnego Cisy koło Sierakowa (Wyżyna Woźnicko-Wieluńska). Acta Botanica Silesiaca 10: 141-153.

Stebel A., Plášek V. (2001): Dicranoweisia cirrata and Orthodicranum tauricum (Musci) in the Polish and Czech part of upper Silesia - distribution and ecology. Natura Silesiae Superioris 5: 21-31.

Stebel A., Rosadziński S., Wolski G.J., Staniaszek-Kik M., Fudali E., Armata L., Szczepański M. (2012a): Further spreading of Orthodicranum tauricum (Bryophyta, Dicranaceae) in Poland. Roczniki Akademii Rolniczej w Poznaniu 391, Botanica - Steciana 16: 75-79.

Stebel A., SmolińsKa D. (2013): Nowellia curvifolia (Marchantiophyta) in the Dolina Żabnika Nature Reserve (Silesia Province, Poland). Opole Scientific Society, Nature Journal 46: 28-33.

Stebel A., Virchenko V.M., Plášek V., Ochyra R., BedNAREK-OCHYRA B. (2012b): Range extension of Orthodicranum tauricum (Bryophyta, Dicranaceae) in Central-East Europe. Polish Botanical Journal 57(1): 119-128.

Stebel A., Zubel R., Vončina G., Fudali E., WierzCHOlsKa S., StaniasZek-KIK M., FojciK B., RusińsKa A., SzcZepańsKi M. (2017): Różnorodność gatunkowa mszaków rezerwatu leśnego „Chwaniów” (Góry Sanocko-Turczańskie, Karpaty Wschodnie). Acta Botanica Silesiaca 12: 5-20.

SZWEYKOWSKi J. (1969): H. 213. Nowellia curvifolia (Dicks.) Mitten. W: J. Szweykowski, T. Wojterski 
(red.). Atlas of geographical distribution of spore plants in Poland. Vol. 6. Series IV. Liverworts (Hepaticae). Polska Akademia Nauk, Poznańskie Towarzystwo Przyjaciół Nauk, Poznań.

SzWEYKOWSKI J. (2006): An annotated checklist of Polish liverworts and hornworts. - Krytyczna lista wątrobowców i glewików Polski. Biodiversity of Poland. Vol. 4. W. Szafer Institute of Botany, Polish Academy of Sciences, Kraków.

Urbanek-Rutowicz H. (1969): Udział i rola diagnostyczna mszaków oraz stosunki florystyczno-fitosocjologiczne w przewodnich zespołach roślinnych regionu łódzkiego i jego pobrzeży. Wydawnictwo Uniwersytetu Łódzkiego, Łódź.

WierzGoń M., Fojcik B. (2014): Martwe drewno jako ostoja różnorodności mszaków w lesie gospodarczym. Studia i materiały CEPL w Rogowie 41(4): 212-222.

Wolski G.J., Fudali E. (2013): Contribution to the bryoflora of Central Poland. Mosses and liverworts of the Jodły Oleśnickie nature reserve (Łódź voivodeship). Parki Narodowe i Rezerwaty Przyrody 32(3): 3-23.

WolsKi G.J., Fudali E. (2014): Contribution to the bryoflora of Central Poland. Mosses and liverworts of the Kruszewiec nature reserve (Łódź province). Parki Narodowe i Rezerwaty Przyrody 33(1): 13-35.

Wolski G.J., JakubowsKa-Gabara J. (2010): Contribution to the bryoflora of Central Poland. Mosses and liverworts of the Łaznów forest reserve. Parki Narodowe i Rezerwaty Przyrody 29(2): 5-62.
Wolski G.J., Woziwoda B., Pawicka K. (2012): Mszaki rezerwatu „Jamno”. Biuletyn Szadkowski 12: 159-170.

ZARZĄDZENIE nr 17/2013 Regionalnego Dyrektora Ochrony Środowiska w Łodzi z dnia 25 czerwca 2013 r. w sprawie ustanowienia planu ochrony dla rezerwatu przyrody „Molenda”. (2013). Dz.Urz. Woj. Łódzkiego z 2013 r., poz. 3638 ze zm.

ŻARNOWIEC J. (2004): Wykorzystanie właściwości bioindykacyjnych mchów w fitosocjologii. Zeszyty Naukowe ATH, Inżynieria Włókiennicza i Ochrona Środowiska 14(5): 217-232.

Żarnowiec J., Klama H., MuŁenKo W. (1996): The differentiation of forest communities and distribution of cryptogamous plants. W: J.B. Faliński, W. Mułenko (red.). Cryptogamous plants in the forest communities of Białowieża National Park. Functional groups analysis and general synthesis (Project CRYPTO). Phytocoenosis 8 (N.S.), Archivum Geobotanicum 6: 163-172.

Żarnowiec J., Stebel A., Chmura D. (2020): The alien moss Orthodontium lineare Schwägr. in Poland (East-Central Europe) - a summary of nearly forty years of invasion. Biological Invasions 22: $1249-1263$.

Żarnowiec J., Stebel A., Ochyra J. (2004): Threatened moss species in the Polish Carpathians in the light on a new Red list of mosses in Poland. W: A. Stebel, R. Ochyra (red.). Bryological studies in the Western Carpathians. Sorus, Poznań: 9-28. 